ARTIGOS

\title{
Educação e violência: uma reflexão a partir da ontologia do ser social
}

\section{Education and violence: a reflection from the ontology of social being}

Hormindo Pereira de Souza Júnior ${ }^{\mathrm{i}}$

Celeste Deográcias de Souza Bitencourt ii

Daniel Handan Triginelli iii

\begin{abstract}
i Departamento de Administração Escolar, Faculdade de Educação, Universidade Federal de Minas Gerais, Belo Horizonte, MG, Brasil. hormindojunior@gmail.com

ii Secretaria Municipal de Educação de Betim, Betim, MG, Brasil. celdeminasfae@yahoo.com.br

iii Faculdade de Educação, Universidade Federal de Minas Gerais, Belo Horizonte, MG, Brasil.

daniellic.bchistoria@yahoo.com.br
\end{abstract}

\begin{abstract}
Resumo
A partir da leitura imanente de textos que compõem o aparato teórico da produção intelectual dos filósofos Marx, Lukács e Mészáros, em particular na perspectiva desse último, devido à sua atualidade, este artigo se propõe a contribuir com o debate em torno da educação e da violência, que é possibilitada e praticada pelas bases que estruturam a lógica da propriedade privada na sociedade de classes. Nos textos analisados, esses filósofos, e em particular Mészáros, explicitam a essência da violência no sistema do capital e a incidência dessa nos demais complexos sociais, como a educação, ao mesmo tempo em que apontam para as condições necessárias à superação da ordem produtora de violência rumo à emancipação humana. A leitura imanente dos textos matrizados por uma ontologia do ser social possibilita uma análise profícua do complexo social da violência que envolve a dimensão da política e da educação.
\end{abstract}

Palavras-chave: educação, violência, ontologia do ser social 


\begin{abstract}
From the immanent reading texts that make up the theoretical apparatus of the intellectual production of Marx philosophers, Lukacs and Mészáros, this article aims to contribute to the debate around education and violence, which is made possible and practiced by the bases that structure the logic of private property in class society. In the evaluated, these philosophers explain the essence of violence in the capital system, and the incidence of other social complex as education, while pointing to the conditions necessary to overcome the producer of violence order towards buman emancipation. The immanent reading of the texts matrices by an ontology of social being in provides a useful analysis of the social complex of violence involving the dimension of politics and education.
\end{abstract}

Keywords: education, violence, ontology of social being

\title{
Introdução
}

Hoje em dia nada importa, a não ser o dinheiro; a riqueza gera honras, amizades; o pobre está por toda parte subjugado. (Ovídio, em Os Fastos, I, 218 - citado pela Rainha Elizabeth I “após um giro pela Inglaterra”)

Abbagnano (2014) nos informa, em seu dicionário, que violência se constitui, primeiro, em uma “ação contrária à ordem ou à disposição da natureza. Nesse sentido, Aristóteles distinguia o movimento segundo a natureza e o movimento por violência: o primeiro leva os elementos ao seu lugar natural; o segundo afasta-os". Porém, ele nos informa ainda que a violência é resultado de "ação contrária à ordem moral, jurídica ou política. Nesse sentido, fala-se em 'cometer' ou 'sofrer' violência'. Continuando seu percurso para tentar nos informar sobre esse importante verbete, diz-nos 


\section{pro.posıções}

eISSN 1980-6248

assim, Sorel fez a distinção entre a violência que se destina a criar uma sociedade nova e a força, que é própria da sociedade e do estado burguês. "O socialismo deve à violência os altos valores morais com que oferece salvação ao mundo moderno”. (pp. 1197-1198)

Como poderíamos compreender a gênese da violência que cada vez provoca mais destruição, em todos os campos da vida humana, e perspectivar uma educação que nos possibilite construir a plenitude da emancipação humana?

No livro O Capital, no capítulo sobre a acumulação primitiva, Karl Marx (2013, pp820-821) apresenta a transição do modo de produção feudal para o modo de produção capitalista. Para ele, a chamada acumulação primitiva é um processo histórico que priva o trabalhador dos seus meios de produção por meio de ações extremamente violentas. A expulsão dos camponeses de sua base fundiária possibilitou, por um lado, a derrocada das velhas instituições feudais, com o fim das terras comunais e a sua transformação em propriedades socialmente concentradas e, por outro lado, a produção de mão de obra barata lançada ao mercado de trabalho.

Portanto, podemos notar que, para Marx, a violência desempenha um papel primordial na história, podendo ser um instrumento por meio do qual se efetiva uma nova dinâmica social. Conforme célebre passagem do capítulo citado: "A violência é a parteira de toda velha sociedade que está prenhe de uma nova. Ela mesma é uma potência econômica" (pp. 820-821). Essa observação é fundamental, pois nesse caso a alavanca para o desenvolvimento e a consolidação do capitalismo como modo de produção hegemônico passa a ser concebida a partir de sua derivação de fatores violentamente realizados. No entanto, é importante frisar que a formação social capitalista não emerge de maneira súbita: esse processo já estava em andamento com as transformações das forças produtivas. Por isso, Marx (2013) adverte que tais fenômenos violentos de expropriação camponesa serão utilizados para "ativar artificialmente o processo de transformação do modo feudal de produção em capitalista e para abreviar a transição" (p. 821). Depois de tais apontamentos, vale ressaltar que Marx toma por base o processo ocorrido na Inglaterra, país cujos acontecimentos possibilitaram ao autor analisar a história da acumulação primitiva em sua forma clássica. Mas as formulações de Marx - graças às suas próprias indicações permitem repensar esse processo em suas características essenciais para a análise de outras épocas históricas ou mesmo em outros países. 


\section{pro.posıções}

Friedrich Engels (1979), ao discutir com o Sr. Dühring, por volta de 1878, entende que a política (por exemplo, a dominação de Sexta-feira por Robinson - baseada na força) e, portanto, a violência constituem a essência da produção e da distribuição dos bens necessários à vida humana. Tudo está (estaria) suficientemente demonstrado pelo famoso pecado original, em que víamos Robinson escravizar Sexta-feira? "Esta escravização era um ato de violência e, portanto, um ato político" (p.137).

Nessa monumental passagem sobre a teoria da violência, Engels (1979), no AntiDubring, afirma que:

o avassalamento do homem como servo, qualquer que seja a forma que apresente, pressupõe, em quem o avassala, o poder de dispor sobre os meios de trabalho, sem os quais o servo não lhe serviria para nada, e pressupõe, na instituição da escravidão, além disso, o poder de dispor dos meios de vida indispensáveis para o sustento do escravo. Pressupõe, assim de qualquer maneira, um certo nível patrimonial superior ao grau médio de fortuna. Perguntamos, agora, de onde é que saiu esta diferença? É fora de dúvida que pôde ter saído do roubo, isto é, da violência, mas esta não é a única explicação possível, pode também ser o fruto do trabalho, do furto, ou de uma transação comercial ou de uma fraude. Ainda mais: para que alguma coisa possa ser roubada é mister tenha alguém criado, com o seu trabalho, aquilo que se lhe rouba. (p.139)

Não é a violência que produz a apropriação privada dos frutos do trabalho humano. É, ao contrário, a apropriação privada dos frutos do trabalho humano que produz a violência. Não é um mero ato de vontade, pressupõe, pelo contrário, condições prévias bastante reais para o seu exercício, a saber: "instrumentos, entre os quais, o mais perfeito esmaga o mais imperfeito" (p.139).

Finaliza Engels (1979) essa brilhante passagem nos dizendo que,

para o Sr. Dühring, a violência é a maldade absoluta. O primeiro ato de força é, em sua Bíblia, o pecado original, reduzindo-se todo o seu arrazoado a um sermão jeremíaco sobre o contágio do pecado original em todos os fatos históricos, e sobre a infame deturpação de todas as leis naturais e sociais por esse poder satânico, que é a força. Sabemos nós que a violência desempenha também, na história, um papel muito diferente, um papel revolucionário; sabemos que ela é, também, para usar uma expressão de Marx, a parteira de toda a sociedade antiga, que traz em suas entranhas uma outra nova; que é ela um instrumento por meio do qual se faz efetiva a dinâmica social, fazendo saltar aos pedaços as formas políticas fossilizadas e mortas. Mas, a respeito de tal aspecto nada nos diz o Sr. Dühring. Reconhece unicamente, entre suspiros e gemidos, que, para derrubar o regime de exploração, não há outro remédio senão usar a violência; desgraçadamente, acrescenta, pois o emprego da violência desmoraliza sempre a quem a utiliza. E diz-nos essas palavras, 


\section{pro.posições}

eISSN 1980-6248

esquecendo-se do elevado impulso moral e espiritual que emana de toda revolução triunfante! E diz-nos tal coisa aqui, na Alemanha onde um choque violento - que se pode impor em caso necessário, ao povo (quem o duvida?) - teria ao menos a vantagem de varrer da consciência nacional essa espécie de submissão servil que dela se apoderou desde a humilhação da guerra dos Trinta Anos! (p.161)

Sobre a questão da violência, da educação e da necessidade de emancipação humana também se debruçam Lukács e Mészáros, que demonstram, em suas vidas e obras, comprovada preocupação com a superação da ordem violenta imposta pela propriedade privada dos frutos do trabalho humano.

Esses autores visam, portanto, a um processo radical de transformação social e não apenas de reformas, mais ou menos profundas, como vemos de forma generalizada serem apregoadas desde a época de Marx, e mais intensamente em nossos dias, sob a forma das tão consagradas reformas políticas, educacionais, de ajustes econômicos, etc. Contra as perspectivas reformistas, Marx elaborou a Crítica do programa de Gotha, também as combate em Sobre a questão judaica e nos manuscritos econômico-filosóficos, entre outras obras. $\mathrm{Na}$ perspectiva da superação, também Lukács, elabora sua Para uma ontologia do ser social e, no mesmo espírito, prossegue Mészáros em sua principal obra Para além do capital e quando tematiza também sobre a educação para além do capital e sobre o socialismo do século XXI.

Ou seja, para a ontologia do ser social, que matriza a filosofia de Marx, Lukács e Mészaros, não nos parece que a essência dos fenômenos seja perfeitamente explicitada pelo estudo da sua forma. Não é a forma que determina a essência, mas vice-versa. Esse nos parece o procedimento adequado, quando buscamos ir além dos idealismos. Portanto, buscar a verdade na radicalidade da essência para além da mera aparência e de suas formas.

\section{Trabalho e violência: a perspectiva de Lukács}

Entendemos que a problemática que envolve a violência está diretamente relacionada ao contínuo processo de construção da história humana. O ser social, em seu 


\section{pro.posições \\ eISSN 1980-6248}

processo de desenvolvimento material e histórico, em meio ao conjunto da totalidade categorial que o compõe, alcança níveis cada vez mais sofisticados no seu processo de relação com a natureza mediada pelo trabalho.

Como resultado desse percurso, o ser social desenvolve, em cada período histórico, estruturas cada vez mais complexas de sociedade, até estruturar formas de organização societárias pautadas pela lógica mais apropriada à dinâmica do capital. Seu consequente desdobramento culmina na propriedade privada dos meios de produção. Esse é o ponto que, a partir dos autores anunciados, compreendemos ser a gênese da violência. Entretanto, no interior do desenvolvimento do trabalho e das forças produtivas, a condução dada pelo ser social em direção à sua humanização coloca as categorias de formação humana e emancipação sociais inseparavelmente entrelaçadas com a categoria trabalho.

Lukács dedica-se a compreender e expor, com notável profundidade, essa mediação fundamental da relação entre o homem e a natureza, fundadora do ser social. Nos termos de Lukács (2013):

é claro que jamais se deve esquecer que qualquer estágio do ser, no seu conjunto e nos seus detalhes, tem caráter de complexo, isto é, que as suas categorias, até mesmo as mais centrais e determinantes, só podem ser compreendidas adequadamente no interior e a partir da constituição global do nível de ser que se trata. E mesmo um olhar muito superficial ao ser social mostra a inextricável imbricação em que se encontram suas categorias decisivas, como o trabalho, a linguagem, a cooperação e a divisão do trabalho, e mostra que aí surgem novas relações de consciência com a realidade e, por isso, consigo mesma etc. (p. 41)

Para o filósofo húngaro não é possível compreender, de maneira adequada, essas categorias isoladamente. Para se alcançar e conhecer a totalidade do ser social, Lukács (2013) reivindica:

ao método marxiano das duas vias, já por nós analisado: primeiro decompor, pela via analítico-abstrativa, o novo complexo do ser, para poder, então, a partir desse fundamento, retornar (ou avançar rumo) ao complexo do ser social, não somente enquanto dado e, portanto, simplesmente representado, mas também compreendido em sua totalidade real. (p. 42) 


\section{pro.posições}

eISSN 1980-6248

Para compreendermos os problemas envolvendo a violência na sociabilidade humana, como ato que afeta o ser social em seu processo material e histórico de produção e reprodução da vida, entendemos ser necessário, respeitando os limites deste artigo, percorrer o processo de constituição do ser social. Esse se funda no salto ontológico alcançado pelo trabalho, conforme nos informa Lukács (2013). Dessa maneira, o trabalho é a categoria que possibilita ao ser social sua lenta e progressiva passagem para o estado orgânico, que, em um determinado momento histórico, ocorre e, aqui, "já não nos encontramos dentro da esfera da vida orgânica, mas em superação de princípio, qualitativamente, ontológica" (p. 45).

Ao reconhecermos que, no ato de trabalhar, o ser social deixa sua condição puramente biológica e se eleva a um estágio ontologicamente superior de existência, se autoconstituindo como ser social que se põe no mundo e o transforma, ao mesmo tempo em que transforma a si próprio, identificamos, mesmo reconhecendo que não há como datar quando o ato ocorre em si, mas somente identificar, por meio do desenvolvimento de estudos que demonstram os traços civilizatórios deixados pelas civilizações anteriores, elementos que possibilitam desnudar o percurso da construção material e social do mundo humano.

Desse modo é enunciada a categoria ontológica central do trabalho: através dele realiza-se, no âmbito do ser material, um pôr teleológico enquanto surgimento de uma nova objetividade. Assim, o trabalho se torna modelo de toda a práxis social, na qual, com efeito - mesmo que através de mediações às vezes muito complexas -, sempre se realizam pores teleológicos, em última análise, de ordem material. (Lukács, 2013, p. 47)

Como Lukács bem coloca, esse processo é possível pelo fato de, na constituição do trabalho, ocorrer o desdobramento categorial e, submetido à categoria fundante, estar presente a categoria da teleologia ${ }^{1}$, inexistente nos demais seres orgânicos. No trabalho,

\footnotetext{
${ }^{1}$ Sobre a teleologia e o pôr teleológico, Lukács (2013) desenvolve uma profunda análise. Em Para uma Ontologia do Ser Social, o filósofo húngaro procura esmiuçar a incompreensão do entendimento sobre a teleologia que é generalizada como um pôr teleológico, como uma forma de entender a realidade, se constituindo, por exemplo, como base, além de ser posta no centro de compreensão e explicação das coisas que envolvem a existência humana pelo pensamento religioso e tendo, também, relevo semelhante em filosofias anteriores, mesmo as mais avançadas, como forma de oferecer sentido a existência. "A referência que fazemos às religiões está fundada na constituição da teleologia enquanto categoria ontológica objetiva. Vale dizer que, enquanto a causalidade é um princípio de automovimento que repousa sobre si próprio e
} 


\section{pro.posıções}

existe em si a contínua efetivação de "por teleológicos" materializando a transformação do idealmente existente nas coisas existentes no mundo, ou seja, partindo da casualidade existente nas coisas transformadas às quais, em si, a produção humana agrega valor de uso para a satisfação de suas necessidades.

Para a satisfação das necessidades humanas, além de ter idealmente o projeto do que se pretende produzir, é preciso conhecer os meios que possibilitarão alcançar tal objetivo. Também nesse caso, é necessário tanto conhecer as propriedades dos objetos utilizados na objetivação do projeto, como reconhecer as propriedades causais que compõem o objeto e contêm em si a possibilidade de atender a demanda. Por essa razão, não há como constituir uma hierarquia entre causalidade e teleologia, como pretenderam as filosofias pré-marxianas e a teologia, trata-se de um processo em que, em sua totalidade, participam causalidade e teleologia. Lukács (2013) argui que,

a investigação dos meios para a realização do pôr do fim não pode deixar de implicar um conhecimento objetivo da gênese causal das objetividades e dos processos cujo andamento pode levar a alcançar o fim posto. No entanto, o pôr do fim e a investigação dos meios nada podem produzir de novo enquanto a realidade natural permanecer o que é em si mesma, um sistema de complexos cuja legalidade continua a operar com total indiferença no que diz respeito a todas as aspirações e ideias do homem. Aqui a investigação tem uma dupla função: de um lado, evidencia aquilo que em si governa os objetos em questão, independentemente de toda consciência; de outro, descobre neles aquelas novas conexões, aquelas novas possibilidades de funções através de cujo pôr-em-movimento tornam efetível o fim teleologicamente posto. (p. 54)

A partir do desenvolvimento exposto, o homem passa a produzir conhecimento sobre as coisas existentes e construir, além das coisas necessárias à sua condição de vida, conhecimento e domínio sobre a realidade que está externa a ele. Os meios de produção, a

mantém esse caráter mesmo quando uma cadeia causal tenha seu ponto de partida num ato de consciência, a teleologia, em sua essência, é uma categoria posta: todo processo teleológico implica o pôr de um fim e, portanto, um mero elevar à consciência, como acontece com outras categorias e especialmente com a causalidade; ao contrário, aqui, com o ato de pôr, a consciência dá início a um processo real, exatamente ao processo teleológico. Assim, o pôr tem, nesse caso, um caráter irrevogavelmente ontológico. Em consequência, conceber teleologicamente a natureza e a história implica não somente que ambas possuem um caráter de finalidade, que estão voltadas para um fim, mas também que sua existência, seu movimento no conjunto e nos detalhes devem ter um autor consciente. O que faz nascer tais concepções de mundo, não só nos filisteus criadores de teodiceias do século XVIII, mas também em pensadores profundos e lúcidos como Aristóteles e Hegel, é uma necessidade de existência, o curso do mundo e até os acontecimentos da vida individual - e estes em primeiro lugar - tenham um sentido" (p. 48). 


\section{pro.posições}

eISSN 1980-6248

investigação e o desenvolvimento constante deles passam a ser uma nova necessidade da condição de existência. O homem já não mais se limita a satisfazer as necessidades imediatas, interessa ao ser social criar as condições e os meios a partir do conhecimento e do domínio da natureza, que possibilitem a satisfação permanente de tais necessidades.

Em primeiro lugar, Hegel sublinha, de um modo geral com razão, a duração mais longa dos meios relativamente ao fins e satisfação imediatos. É claro que, na realidade, tal contraposição nunca é tão rígida como Hegel apresenta. Porque, embora as "satisfações imediatas" singulares certamente "passem" [ênfases do autor] e sejam esquecidas, a satisfação das necessidades também possui persistência e continuidade quando se considera a sociedade como um todo. (Lukács, 2013, p. 58)

Por isso, Lukács (2013) quanto à proposição de Hegel de eleger a predominância dos meios em relação à satisfação das necessidades, realiza a confrontação de Marx, quando coloca que: "podemos ver como o consumo não apenas mantém e reproduz a produção, mas também exerce, por sua vez, certo influxo sobre a produção" (p. 58). Dessa maneira, partindo de Marx, o filósofo húngaro entende que “a produção é o momento predominante naquela relação (aqui: os meios no pôr teleológico), enquanto a contraposição hegeliana, em consequência de suas demasiado bruscas confrontações, deixa de lado seu significado social real” (p. 58).

Lukács (2013), em segundo lugar, confere acerto à colocação de Hegel, quando esse explicita que, graças ao meio, o homem amplia seu domínio sobre a natureza exterior, mesmo que, ao final do processo, ele permaneça submetido a ela. Entretanto, realiza o movimento de avanço ou superação da posição hegeliana, ao demonstrar com maior intensidade, a partir de Marx, a superioridade dos meios.

No entanto, a exposição hegeliana dever ser concretizada, uma vez que a sujeição certamente se refere, no imediato, à natureza - como já vimos, o homem só pode pôr aqueles fins cujos meios adequados à sua efetivação domina de fato -, mas, em última análise, trata-se realmente de um desenvolvimento social, isto é, daquele complexo que Marx chama de metabolismo do homem, da sociedade, com a natureza, no qual não há dúvida que o momento social não pode deixar de ser o momento predominante. $\mathrm{E}$ com isso, a superioridade do meio é sublinhada ainda com maior força do que no próprio Hegel. (p. 58) 


\section{pro.posıções \\ eISSN 1980-6248}

A partir do desenvolvimento material e histórico do complexo categorial exposto, o ser social desenvolve exponencialmente a vida social, a sociabilidade e, em consequência, seu domínio sobre a realidade externa a si e a produção de coisas úteis na constituição do mundo humano e das condições adequadas para sua existência. Nesse percurso, o homem desde suas primeiras formações sociais - as mais primitivas até o desenvolvimento e a consolidação da forma de complexo mais elaborada -, até nosso atual momento histórico, que seja o capitalismo, ocupa-se em gerar valor de uso à produção de coisas úteis à vida social e à particular.

Com o desenvolvimento histórico e social, o homem amplia a produção de valores de uso, aumenta potencialmente o surgimento de novas necessidades a serem satisfeitas. Conforme Lukács (2013):

na gênese ontológica do valor, devemos partir, pois de que no trabalho como produção de valores de uso (bens) a alternativa do que é útil ou inútil para a satisfação das necessidades está posta como problema de utilidade, como elemento ativo do ser social. (p. 111)

O avanço das forças produtivas se relaciona com esse processo humano, efetiva a produção a partir da divisão social do trabalho e gera valores econômicos (valores de troca).

Como poderiam, pois, seus pores de valor constituir valor econômico? O próprio valor está presente objetivamente e é exatamente a sua objetividade que determina - mesmo que objetivamente não com a certeza adequada e subjetivamente sem uma consciência adequada - os pores teleológicos singulares, orientados para o valor. (p. 113)

Esse elemento desencadeia uma teia de complexidades em torno da categoria valor, fato que transforma toda a produção de coisas em mercadorias e objetiva em si a economia de tempo, apresentando-se como base para toda a economia. Com o avanço demonstrado, verifica-se a necessidade de regular os tempos de trabalho necessários ao desenvolvimento das práticas sociais em torno da geração de valor pelo trabalho, ao mesmo tempo em que, na singularidade do campo individual, é necessário administrar seu tempo em aprendizado de conhecimentos que lhe possibilitem compor essa nova estrutura social. 


\section{pro.posições}

eISSN 1980-6248

Economia de tempo, a isto se reduz afinal toda economia. Da mesma forma, a sociedade tem de distribuir apropriadamente o seu tempo para obter uma produção em conformidade com a totalidade de suas necessidades; do mesmo modo como o indivíduo singular tem de distribuir seu tempo de forma correta para adquirir conhecimentos em proporções apropriadas ou para desempenhar suficientemente as várias exigências de sua atividade. Economia de tempo, bem como distribuição planificada do tempo de trabalho entre os diferentes ramos de produção, continua sendo também a primeira lei econômica sobre a base da produção. (Marx citado por Lukács, 2013, p. 113)

O processo em questão deveria permitir ao ser social se efetivar no mundo, ampliar seu domínio sobre a natureza, reduzir o tempo necessário à produção e gozar de tempo livre para o desenvolvimento de toda sua potencialidade humana. A esse respeito, nos diz Marx (citado por Lukács, 2013):

Se considerarmos a sociedade burguesa em seu conjunto, a própria sociedade, i.e., o próprio homem em suas relações sociais, sempre aparece como resultado último do processo de produção social. Tudo o que tem forma fixa, como o produto, etc., aparece somente como momento, momento evanescente nesse movimento. O próprio processo de produção imediato aparece aí apenas como momento. As próprias condições e objetivações do processo são igualmente momentos dele, em relações recíprocas, relações que eles tanto reproduzem quanto produzem de maneira nova. É seu próprio contínuo processo de movimento, em que eles renovam a si mesmos, bem como o mundo da riqueza que criam. (p. 115)

Entretanto é esse processo histórico de desenvolvimento das sociedades humanas, o desenvolvimento das forças produtivas e dos conhecimentos necessários à intervenção na realidade existente pelo ser social, que a transforma em seu favor, para satisfazer suas necessidades. Dessa maneira, esse movimento cria complexos categoriais, nos quais aqui não há como adentrar, que permitem ao homem alcançar a produção de riqueza excedente, fundar a sociedade do capital pautada na apropriação privada dos meios de produção e, consequentemente da riqueza socialmente produzida. Ele próprio vê sua única propriedade, a sua força de trabalho, ser transformada em mercadoria, a mais importante, diga-se, no processo produtivo, mas passa a relação estranhada com os objetos e as mercadorias que produz. Nesse sentido, embora seu trabalho estranhado capitalista tenha, em certa medida, imbricada nele sua primária tarefa ontológica de libertá-lo do reino das 


\section{pro.posıções}

e-ISSN 1980-6248

necessidades, ele já não pode cumpri-la, pois somente garante as condições de alcançar a satisfação de suas necessidades básicas.

Esse modelo social de existência realiza a sujeição do trabalho à sua lógica organizativa e transforma seus produtos em mercadorias a serem consumidas no mercado. Aqui consideramos estar a gênese da violência que submete o homem a um processo dialético em direção à condição de efetivação de sua liberdade, ao mesmo tempo que o mantém em processo contraditório no modelo societário capitalista. Tratamos aqui a questão da formação humana como condição educativa ampliada, ou seja, para além da formalidade escolar. O homem se funda a partir do desenvolvimento da categoria trabalho, em sua eterna relação de transformação da natureza. O homem transforma o que é natural e a si próprio para além da formalidade da educação como, geralmente, é tratada nos círculos sociais e acadêmicos. Entendemos que o trabalho cumpre sua função formadora, educa o ser social em sua totalidade mesmo que de forma violenta, quando apropria privadamente os frutos do trabalho social.

\section{Educação e violência: a perspectiva de Mészáros}

István Mészáros tematiza a educação 2 a partir do processo mais amplo de análise do sistema sociometabólico do capital3e, para tal, realiza dois movimentos: o da crítica (negativo) e o da proposição (positivo). Em seu processo de crítica ao sistema do capital, Mészáros (2007) pontua, porém que, na fase ascendente de seu desenvolvimento, esse sistema era imensamente dinâmico e, em muitos aspectos, também positivo, e assim pôde produzir utopias educacionais nobres como a educação moral de Kant e a educação estética de Schiller (pp. 294-295).

\footnotetext{
${ }^{2}$ O tema educacional é tratado, mais especificamente em Mészáros (2006a), capítulo 10 - "A alienação e a crise da educação"; em Mészáros (2007), capítulo 8, originalmente publicado como livro (Mészáros, 2005).

${ }^{3}$ Sua mais importante e grande obra em que analisa o sistema do capital, Mészáros I. (2006b). *** a obra já está nas referências, basta indicar autor e data. Sinalizamos que nesta e nas demais obras aqui mencionadas e mesmo naquelas não referidas neste artigo, Mészáros utiliza-se de uma série de categorias, algumas inéditas, por meio das quais realiza a apreensão da realidade da sociedade contemporânea e do conjunto de mediações que articulam os microcosmos ao macrocosmo da totalidade social em sua reciprocidade dialética. Categorias essas, que não poderão ser aqui explicitadas, pela limitação própria deste espaço, mas que mencionamos para que o leitor interessado possa aprofundar, dentre elas, destacamos: a distinção entre sistema sociometabólico do capital e capitalismo e mediações de primeira ordem e mediações de segunda ordem; crise estrutural do capital, produção destrutiva, trabalho, alienação.
} 


\section{pro.posıções}

Mas, para Mészáros (2011), iniciou-se nos anos 70 do século XX a atual fase decadente da história do capital, caracterizando seu momento descendente. Esse sistema, de controle global de produção e reprodução societária, é fundado na exploração do trabalho. E em sua lógica perversa e expansionista é um processo prático, potencialmente letal de acumulação ampliada da riqueza, cujas contradições e antagonismos profundos atingem os "limites estruturais absolutos do capital", que caracterizam sua "crise estrutural" (pp. 294-295). Essa gera destruição ilimitada, perceptível na crise permanente em todos os domínios da vida, como o econômico, o social, o político, o ecológico, o cultural, o religioso e o educacional, cuja crise, antes inconcebível, pela profundidade e abrangência, põe em risco a própria sobrevivência da humanidade.

A atual conjuntura crítica da história da humanidade, provocada pelo expansionismo do capital com seu potencial de "destruição total da humanidade", é enfatizada por Mészáros, na medida em que analisa o poder de destruição, antes inimaginável, que se encontra hoje à disposição da humanidade, pelo qual se pode alcançar facilmente o completo extermínio da espécie humana, por meio de uma variedade de meios militares, como já testemunhamos no século XX, nas das duas guerras mundiais extremamente destrutivas e no genocídio das armas nucleares, e continuamos a presenciar com as guerras permanentes e injustificadas, ou mesmo produzidas, acima de tudo, pelo poder hegemônico e belicista estadunidense.

A grave ameaça à vida humana deve-se também à natureza destrutiva do controle sociometabólico do capital em nosso tempo. Esse se manifesta pela predominância cada vez maior da "produção destrutiva" em si e pelo processo de devastação do ambiente natural, provocado por essa produção e que põe em risco as condições elementares da própria existência humana no planeta, como comumente ouvimos ser denunciado pela grande mídia como "mudanças climáticas" ou numa abordagem mais crítica que reconhece que "el mundo está atravesando 'límites planetarios' cruciales" e conforme comprovam os estudos dos "prestigiosos científicos climáticos," cuja "la principal preocupación es lo que podría llamarse la 'Gran Fractura' en la relación humana con la naturaleza, debido a que se han atravesado los límites del sistema terrestre (Foster, 2013). 


\section{pro.posições}

Mas a gênese do caráter violento e destrutivo dessa formação social, pautada na dominação e na subordinação estrutural do trabalho ao capital, foi desde sempre denunciada por Marx, segundo Mészáros, como sendo o princípio do bellum omnium contra omenes. Ou nos termos de que a história da humanidade tem sido a história da luta de classes, cuja relação entre os seres humanos na forma conflitiva e adversa foi sempre tida como natural. Marx, segundo Mészáros (2011), desmistifica essa ordem, apresentando o seu caráter histórico e afirmando que deve ser suplantada pela criação e pela consolidação de uma nova ordem social, pautada na igualdade substantiva e gerenciada pelos "trabalhadores/produtores livremente associados" (p. 295).

Mészáros enfatiza a possibilidade e a necessidade do socialismo no século XXI até mesmo como uma "urgência histórica", porque, para ele, não pode haver saída dessa armadilha destrutiva da humanidade sem erradicar o sistema do capital de seu controle do processo sociometabólico estabelecido. Embora o capital continue a negar a possibilidade de ser historicamente superável e insista em sua máxima de que "não há alternativa". Principalmente após a implosão da primeira grande tentativa, no século XX, de estabelecer uma "sociedade pós-capitalista", na URSS e por toda a Europa Oriental.

Mesmo diante dessa conjuntura ideologicamente desfavorável, Mészáros alerta que, dada a crise estrutural cada vez mais profunda da ordem do capital, a instituição bem fundada da alternativa socialista é mais urgente do que nunca. Mas, ao mesmo tempo, devido à "pesada evidência histórica do desenvolvimento de tipo soviético", Mészáros (2007) alerta que "apenas pelo reexame socialista plenamente consciente e autocriticamente comprometido dos passos tomados com intenção emancipatória - tanto no passado como no presente - será possível tornar os fundamentos do socialismo no século XXI mais seguros” (p. 30) e não incorrer nos erros cometidos no século XX.

Segundo Mészáros (2011), a atual conjuntura crítica da história humana e a urgência dramática do tempo demandam soluções duráveis e viáveis, via uma mudança estrutural radical e abrangente na ordem sociometabólica, que traz consigo a exigência de uma redefinição qualitativa das determinações sistêmicas da sociedade, pois ajustes parciais e

\footnotetext{
${ }^{4}$ Esta é mais uma categorização inédita realizada por Mészáros e que, com certeza, não encontra unanimidade no movimento socialista, pois considera a experiência histórica realizada na URSS e que influenciou todo o leste europeu, como uma "sociedade pós-capitalista", e não sociedade socialista ou "socialismo realmente existente", como comumente vimos ser referenciado.
} 


\section{pro.posições}

eISSN 1980-6248

melhorias marginais não são suficientes para cumprir o desafio. Eles podem apenas reproduzir em escala ampliada os perigos identificáveis de forma clara tanto no domínio da destruição econômica e militar como no plano ecológico.

E na consolidação desse sistema, para Mészáros (2007), a educação contribui de forma fundamental por dois processos. Um pela via da doutrinação permanente da maioria esmagadora das pessoas que são submetidas às concepções mais estreitas da "racionalidade instrumental". Sinaliza que, quanto mais "avançada" é a sociedade capitalista, mais é "unilateralmente centrada na produção de riqueza reificada como um fim em si mesma" (p.294) e mais se exploram as "instituições educacionais em todos os níveis, desde as escolas preparatórias até as universidades” (p. 294) que cumpram seu papel na "perpetuação da sociedade de mercadorias" (p.294). O processo de doutrinação a todos impregna com "os valores da ordem social do capital como a ordem natural inalterável, racionalizada e justificada pelos ideólogos mais sofisticados do sistema em nome da 'objetividade científica' e da 'neutralidade de valor"'. Mesmo a educação institucionalizada sendo limitada a alguns poucos anos economicamente convenientes da vida dos indivíduos e sendo aplicada de maneira discriminatória e elitista, o processo de doutrinação realiza-se com êxito por meio do processo da "educação contínua" das pessoas no "espírito de tomar como dado o ethos social dominante, internalizando 'consensualmente', com isso, a proclamada inalterabilidade da ordem natural estabelecida”. Mészáros (2007) explicita que a “educação contínua" obtém êxito porque as

condições reais da vida cotidiana foram plenamente dominadas pelo ethos capitalista, sujeitando os indivíduos - como uma questão de determinação estruturalmente assegurada - ao imperativo de ajustar suas aspirações de maneira conforme, ainda que não pudesse fugir à áspera situação da escravidão assalariada. (p.294)

Mészáros (2006a) qualifica o papel da educação na sociedade dominada pelos imperativos do capital nos termos de que:

além da reprodução, numa escala ampliada, das múltiplas habilidades sem as quais a atividade produtiva não poderia ser levada a cabo, o complexo sistema educacional da sociedade é também responsável pela produção e reprodução da estrutura de valores no interior do qual os indivíduos definem seus próprios objetivos e fins específicos. (p. 263) 


\section{pro.posições}

Assim, Mészáros (2006a) sintetiza que, numa sociedade capitalista, a educação tem duas funções principais: 1 - "a produção das qualificações necessárias ao funcionamento da economia", e 2 - "a formação dos quadros e a elaboração dos métodos de controle político” (p.275). É nesse sentido que devemos considerar a crise da educação formal no marco mais amplo da crise estrutural do capital, pois a "educação formal está profundamente integrada na totalidade dos processos sociais, e mesmo em relação à consciência do indivíduo particular suas funções são julgadas de acordo com sua raison d`etre identificável na sociedade como um todo” (p. 275). Sendo assim,

a crise atual da educação formal é apenas a "ponta do iceberg". O sistema educacional formal da sociedade não pode funcionar tranquilamente se não estiver de acordo com a estrutura educacional geral - isto é, com o sistema específico de "interiorização" efetiva da sociedade em questão. A crise das instituições educacionais é então indicativa do conjunto de processos dos quais a educação formal é uma parte constitutiva. A questão central da atual "contestação" das instituições educacionais estabelecidas não é simplesmente o "tamanho das salas de aula", a "inadequação das instalações de pesquisa" etc., mas a razão de ser da própria educação. Desnecessário dizer: tal questão envolve inevitavelmente não só a totalidade dos processos educacionais, "desde a juventude até a velhice", mas também a razão de ser dos instrumentos e instituições do intercâmbio humano em geral [ênfases no original]. Se estas instituições - incluindo as educacionais foram feitas para os homens, ou se os homens devem continuar a servir às relações sociais de produção alienadas - esse é o verdadeiro tema do debate. (p. 275)

Nessa perspectiva de questionamento dos próprios fundamentos da sociedade como tal e de seus instrumentos e instituições em sua totalidade, inclusive os educacionais, Mészáros (2007) insiste que somente a "instituição e a consolidação da alternativa hegemônica do trabalho social ao controle sociometabólico do capital pode oferecer uma saída para as contradições e antagonismos de nosso tempo"(p. 308). E esta não pode sob nenhum aspecto funcionar sem abraçar positiva e conscientemente as forças dinâmicas da mudança em todos os níveis da vida individual e social, incluindo as determinações estruturalmente vitais da reprodução material e cultural da sociedade, ou seja, uma transformação qualitativa oniabrangente.

É nesse quadro de análise do sistema do capital como um sistema de controle global, que subordina tudo a sua lógica expansionista e destrutiva, mas que é vislumbrado por Mészáros, e já era autoevidente para Marx, como uma contingência histórica que tem a possibilidade e a necessidade de ser superada, que Mészáros analisa a educação, tanto em 


\section{pro.posições}

eISSN 1980-6248

seu papel de reprodutor da atual ordem estabelecida como em seu papel transformador de uma nova ordem social.

Ao analisar a atual realidade social como uma grave crise estrutural do capital, Mészáros (2007), indica que hoje a “inflexível alternativa é o socialismo ou barbárie, senão a completa aniquilação do gênero humano" (p. 227). Enfatiza que este é um fato histórico que clama por um conjunto de estratégias coerentes, de uma mudança radical, que possam ser vitoriosas. Assim Mészáros dá sua contribuição propositiva, ao elaborar os principais objetivos e características da necessária transformação socialista ${ }^{5}$, ou seja, indica-nos alguns princípios orientadores que devem nortear a elaboração de estratégias viáveis para o futuro próximo e o mais distante.

Alerta que uma genuína transformação socialista se constitui numa totalidade estreitamente integrada. Assim, esses princípios orientadores "são em certo sentido, pontos arquimedianos que sustentam a si mesmos e uns aos outros por meio de suas determinações recíprocas e implicações globais" (Mészáros, 2007, p. 225). Todos têm igual importância, no sentido de que nenhum deve ser negligenciado ou omitido. Tematiza sobre oito princípios orientadores, sendo que a "educação" (perspectivada como "o desenvolvimento contínuo da consciência socialista") comparece como o oitavo deles. Embora a educação nos interesse mais diretamente, os demais serão mencionados a seguir, apenas para visualizarmos a totalidade social em que essa é incorporada.

Os demais princípios orientadores são: $1^{\circ}$ - a busca da "irreversibilidade" ("o alvo da transformação socialista sustentável deve ser firmemente reorientado a partir da deposição do capitalismo - administrável apenas de modo estritamente temporário - à completa erradicação do processo sociometabólico do capital”); $2^{\circ}$ - "participação" ("a progressiva transferência do poder de decisão aos 'produtores associados"); $3^{\circ}$ - "igualdade substantiva" ("a condição absoluta de sustentabilidade"); $4^{\circ}$ - "planejamento" ("a necessidade de superar o abuso do tempo cometido pelo capital"); $5^{\circ}$ - "crescimento qualitativo em utilização" (a única economia viável”); $6^{\circ}$ - "o nacional e o internacional” ("sua complementaridade dialética em nosso tempo"); $7^{\circ}$ - "a alternativa ao parlamentarismo" (a unificação das esferas da reprodução material e da política") (Mészáros, 2007, pp. 226-316).

${ }^{5}$ Ver o capítulo 9, “O socialismo do século XXI”, em Mészáros (2007). 


\section{pro.posições \\ e-ISSN 1980-6248}

A concepção de educação como o "desenvolvimento contínuo da consciência socialista" na sociedade como um todo é um processo complexo, que se articula como indicado a todos os outros princípios orientadores do processo de transição socialista, apontados por Mészáros, e sobre o qual podemos, neste espaço, apenas sintetizar que essa concepção se afasta radicalmente das práticas educacionais dominantes sob o capitalismo e só pode realizar-se, por meio do que diz Marx, "quando se descarta a forma burguesa estreita" e se pode afirmar o "indivíduo social rico".

Assim a concepção de educação como o "desenvolvimento contínuo da consciência socialista" só pode realizar-se, conforme Mészáros (2007) e retomando o próprio Marx, por meio da “educação concebida como a auto-educação radical dos indivíduos sociais, no curso de sua 'alteração que só pode ter lugar em um movimento prático, em uma revolução', somente nesse processo podem os indivíduos sociais tornar-se simultaneamente educadores e educados" (p.314). E com isso superar a "dicotomia conservadora de todas as concepções elitistas que dividem a sociedade em seletos 'educadores' misteriosamente superiores e o resto da sociedade consignada a sua posição permanentemente subordinada de 'educados', como realçado por Marx” (p. 314), em suas teses Ad Feuerbach. Portanto, o processo de uma educação para além das determinações alienantes, desumanizadoras e destrutivas do capital, deve visar, por conseguinte, a um processo emancipatório mais amplo de toda a humanidade.

\section{Conclusão}

Acompanhando as análises de Mészáros, a educação formal está profundamente articulada ao modo de produção correspondente. Trata-se de "processos de internalização", que asseguram os parâmetros reprodutivos gerais do sistema do capital. A educação contínua (formal) das pessoas é responsável pela produção, reprodução e perpetuação da sociedade de mercadorias e, portanto, de todas as formas de violência geradas por essa produção.

Mészáros considera as instituições formais de educação como parte importante do sistema global de "internalização" e ressalta que a dominação ideológica da sociedade 


\section{pro.posıções}

eISSN 1980-6248

prevalece por toda a vida. A partir dessa ideia, ele reforça que a educação formal não é uma força primária que consolida o sistema do capital e por isso não é capaz de fornecer isoladamente uma alternativa "emancipadora" radical. Além disso, aponta a incoerência de esperar da sociedade mercantilizada a formulação de um ideal educacional emancipador.

Mészáros afirma que nenhum dispositivo de manipulação é homogêneo e uniforme, a ponto de transformar o complexo processo de modelagem da visão geral do mundo, ou seja, nossa concepção de mundo depende da forma como as forças sociais conflitantes se confrontam e se defendem, contribuindo para a manutenção ou para a mudança.

Assim, Mészáros afirma que o potencial emancipador da escola deve abarcar a totalidade das práticas político-educacional-culturais em uma proposta de educação para a vida, com práticas educacionais concretas mais abrangentes, que rompam com o sistema de "internalização", a que ele chama de "contrainternalização", superando as formulações educacionais utópicas e reformistas.

Para Mészáros, uma alternativa educacional significativamente diferente só será possível se rompermos com a lógica vigente e violenta do capital. Ele propõe para o desenvolvimento de uma tomada de posição dos educadores no sentido da formulação de propostas, práticas e históricas em busca da "igualdade substantiva". Para Mészáros (2005) o papel da educação é vital, tanto para a elaboração de estratégias contra as condições objetivas da reprodução como para a mudança consciente dos indivíduos na busca de uma ordem social diferente, assegurando, portanto, as possibilidades de uma transformação plenamente sustentável. Assim, os indivíduos sociais seriam, ao mesmo tempo, "determinantes-determinados de um processo transformador permeado pela mais absoluta reciprocidade entre educação e transformação" (p.72).

Finalmente, os processos que envolvem a objetivação humana são essencialmente históricos. Processos: que objetivam o ser social no mundo; que tornam o homem cada vez mais homem; que o diferenciam essencialmente de sua condição animal; e que, portanto, cada vez mais, em cada época histórica distanciam o ser social (humano) de sua condição animal e são fundamentais para sua plena liberdade, para seu pleno arbítrio. As condições históricas da apropriação privada dos frutos do trabalho humano por limitações essencial e historicamente colocadas não possibilitam a plena objetivação do ser do homem no 


\section{pro.posições}

eISSN 1980-6248

mundo. É um momento histórico fundamental, cuja objetivação possível ainda é em si limitada; humanamente limitada para a completa objetivação do ser social em sua plenitude. Os processos de objetivação no interior da propriedade privada impõem limites à realização plena do humano.

Como nos afirma Marx (2004):

Vimos que significado tem, sob o pressuposto do socialismo, a riqueza (Reichbeit) das carências humanas e, portanto, tanto um novo modo de produção, quanto um novo objeto da produção. Nova atividade da força essencial humana e novo enriquecimento da essência humana. No interior da propriedade privada o significado inverso [itálico adicionado]. Cada homem especula sobre como criar no outro uma nova carência, a fim de força-lo a um novo sacrifício, colocá-lo em nova sujeição e induzi-lo a um novo modo de fruição e, por isso, de ruína econômica. Cada qual procura criar uma força essencial estranha sobre o outro, para encontrar aí satisfação de sua própria carência egoísta. Com a massa dos objetos cresce, por isso, o império (das Reich) do ser estranho ao qual o homem está submetido e cada novo produto é uma nova potência da recíproca fraude e da recíproca pilhagem. $\mathrm{O}$ homem se torna cada vez mais pobre enquanto homem, carece cada vez mais de dinheiro para se apoderar do ser hostil, e o poder de seu dinheiro cai precisamente na relação inversa da massa de produção, ou seja, cresce sua penúria (Bedürftigkit) à medida que aumenta o poder do dinheiro. - A carência de dinheiro é, por isso, a verdadeira carência produzida pela economia nacional e a única carência que ela produz. - A quantidade de dinheiro se torna cada vez mais seu único atributo poderoso; assim como ele reduz todo o ser à sua abstração, reduz-se ele em seu próprio movimento a ser quantitativo. A imoderação e o descomedimento tornam-se a sua verdadeira medida... (p.139)

Os processos de objetivação do ser no interior da propriedade privada, no limite, impedem a plena humanização e reforçam a necessidade da utilização da violência como instrumento necessário à subjugação de um pelo outro. A violência se constitui em instrumento essencialmente necessário às circunstâncias históricas que impõem a apropriação privada dos frutos do trabalho humano. Quanto mais distantes essas condições, mais perto da plena humanidade, portanto, mais objetivado o ser social no mundo humano.

A apropriação privada dos bens necessários e fundamentais para a produção da subsistência humana adquire novos conteúdos e novas formas no interior da sociedade produtora de mercadorias. Para garantir a produção da riqueza, torna-se necessária a expropriação da força de trabalho humana, condição fundamental para sua apropriação privada. E essa se torna condição necessária para a produção da riqueza. Ao expropriar a 
força de trabalho e apropriá-la privadamente, os apropriadores dos bens necessários à produção da subsistência humana apropriam privadamente todos os frutos do trabalho humano. Eis a gênese da violência. Portanto, sua essência e não sua mera forma, sendo a ação política a responsável pela manutenção, disseminação e implementação dos mecanismos fundamentais à realização plena dessa gênese. A superação plena da violência implica necessariamente a superação radical da política e vice-versa. Porém, a superação radical tanto da política quanto da violência somente poderá ocorrer com a superação radical das condições essenciais que lhe dão existência. Ou seja, a superação das condições de apropriação privada dos frutos do trabalho humano. Bases de uma educação de novo tipo: "para além do capital".

\section{Referências Bibliográficas}

Abbagnano, N. (2012). Dicionário de Filosofia. São Paulo: WMF Martins Fontes.

Engels, F. (1979). Anti-Dühring. Rio de Janeiro: Paz e Terra.

Foster, J. B.(2013, diciembre). Marx y la fractura en el metabolismo universal de la naturaleza. Monthly Review, 65(7). Retirado em junho de 2014, de http://www.herramienta.com.ar/herramienta-web-15/marx-y-la-fractura-en-elmetabolismo-universal-de-la-naturaleza.

Lukács, G. (2013). Para uma ontologia do ser sócia II (N. Schneider, I. Tonet, \& R. V. Fortes, trads.). São Paulo/SP: Boitempo.

Marx, K. (2004). Manuscritos econômicos filosóficos. São Paulo: Boitempo.

Marx, K. (2013). O Capital: crítica da economia politica (Livro I). São Paulo: Boitempo. 


\section{pro.posições \\ eISSN 1980-6248}

Mészáros, I. (2005). A educação para além do capital (I. Tavares, trad.). São Paulo: Boitempo.

Mészáros, I. (2006a). A teoria da alienação em Marx (I.Tavares, trad.). São Paulo: Boitempo.

Mészáros, I. (2006b). Para além do capital: rumo a uma teoria da transição (P. C. Castanheira, \& S. Lessa, trads.). São Paulo: Boitempo.

Mészáros, I. (2007). O desafio e fardo do tempo histórico: o socialismo no século XXI. São Paulo: Boitempo.

Mészáros, I. (2011). A crise estrutural do capital (2a ed. rev. e ampliada, F. Cornejo, trad.). São Paulo: Boitempo.

Submetido à avaliação em 21 de março de 2016; aceito para publicação em 24 de abril de 2016. 